\title{
Shear strength of hollow circular sections
}

\section{Resistência ao cisalhamento de seções circulares vazadas}

F. O. QUEIROZ JUNIOR a

francinaldo.queiroz@anac.gov.br

B. HOROWITZ

horowitz@ufpe.br

\begin{abstract}
The number of buildings higher than 30 floors has shown remarkable growth; many of them are supported on foundations of hollow circular piles This increasing of height of constructions causes an increment of the shear stresses that are transmitted to their foundations, however these elements are more shear critical due to the hollow core. Most of the existing codes are based on shear models for rectangular sections, and guidelines for assessment of shear strength of members with hollow circular cross sections are practically non-existent. This study evaluates, on a comparative basis, the shear strength of elements with hollow circular cross sections, obtained from experimental tests, with values computed using the Canadian Code (CSA A23.3) and using a proposed simple procedure based on the Brazilian standard (NBR 6118).
\end{abstract}

Keywords: shear strength, hollow circular cross section, modified compression filed theory.

\section{Resumo}

O número de edifícios com mais de 30 pavimentos tem apresentado notável crescimento, muitos dos quais apoiados sobre fundações de estacas circulares vazadas. Este aumento da altura das edificações provoca o aumento das tensões de cisalhamento que são transmitidas para suas respectivas fundações, no entanto tais elementos são mais críticos em relação ao cisalhamento devido ao seu núcleo vazado. A maioria das normas existentes é baseada em modelos de cisalhamento para seções retangulares, enquanto que diretrizes para avaliação da resistência ao cisalhamento de membros com seções circulares vazadas são praticamente inexistentes. Este estudo avalia, de forma comparativa, a resistência ao cisalhamento de elementos de seções circulares vazadas, obtida através de ensaios experimentais, com valores calculados utilizando a Norma Canadense (CSA A23.3) e utilizando um procedimento simples proposto baseado na norma Brasileira (NBR 6118).

Palavras-chave: resistência ao cisalhamento, seção circular vazada, teoria do campo de compressão modificada. 


\section{Introduction}

Despite the frequent use of members with hollow circular cross sections, little research work has been done to perform behavior analysis of such members when subjected to bending, shear and normal forces. The codes requirements for designing of elements subjected to shear forces are based on rectangular sections models. Some codes, such as ACI 318 [1], for example, recommend the transformation of circular sections into equivalent rectangular sections, which may be questionable since stirrups contribute differently to the shear strength of both sections.

The literature presents a few models developed especially for members with hollow circular cross sections, and the number of specimens tested is very limited. JENSEN \& HOANG [2] considered that the shear strength of a specimen will, depending on the axial compressive force, be governed either by shear failure in cracked concrete or in uncracked concrete. They proposed a combination of a classical upper bound model with the so-called crack sliding model. Figure 1 shows typical shear collapse of a hollow cored specimen tested by KISHIDA et al. [3].

VÖLGYI et al. [4] presents a model based on the analysis of potential rupture sections subjected to bending and shear. It was applied a compatibility criteria which considers the way that a member carry the applied load. It is also presented an analogy between the failure of the concrete compression zone and the failure of a soil along a sliding surface.

COLLINS et al. [5] defends the use of the Modified Compression Field Theory (MCFT) to predict the shear strength for circular elements. Several authors all over the world consider the MCFT one of the most accurate models on determining the shear strength of members. According to VÖLGYI et al. [4] the final draft of FIB Model Code for Concrete Structures [6] implements three approximation levels to calculate the shear resistance of members with shear reinforcement; and the approximation level III, which is based on the MCFT, is the most accurate one. However the MCFT was not considered a simple method by the designers, then BENTZ et al. [7] presented a simplification for the model which formed the basis of AASHTO LFRD [8] and CSA A23.3 [9].

NBR 6118 [10] considers two calculation models, both based on the truss model along with complementary resistant mechanisms that develop inside the element. The truss model has been considered the basis for the design of transverse reinforcement of concrete beams for over half a century, and is far from being overcome. Researches suggest only modifications or additions to its theory, maintaining its fundamental aspect, the analogy between the beam of reinforced concrete, after cracked, and a truss.

For the particular case of hollow circular section there is lack of experimental data. As a consequence, proposed models found in the literature are either limited or too complex for routine design work, like the model proposed By VÖLGYI et al. [4]. Additionally, the main reinforced concrete codes do not establish parameters to determine the shear strength of members with hollow circular sections. In this context it is up to the designer to determine such parameters, which many times are established without any technical support. Therefore, this paper aims to propose a suggestion to NBR 6118 of safe parameters $\left(b_{\mathrm{w}}\right.$ and $\left.d\right)$ that allows to include a simple and safe analysis of the shear strength of members with hollow circular cross sections subjected to bending, shear and axial force.

\section{Methodology}

Values for parameters $b_{w}$ and $d$ for hollow circular sections submitted to shear, bending and axial force are here discussed. In order to achieve such goal, this study was divided into six methodological steps, which are: searching for codes and experimental data; establishing parameters based on the existing codes and studies found in the literature; computation of the shear strength using the proposed models adopted by Brazilian and Canadian Codes, including the new parameters determined by the previous step; and comparison of the results found, using the codes, with

Figure 1 - Collapse of the member JP12 001535 tested by KISHIDA ef al (3)

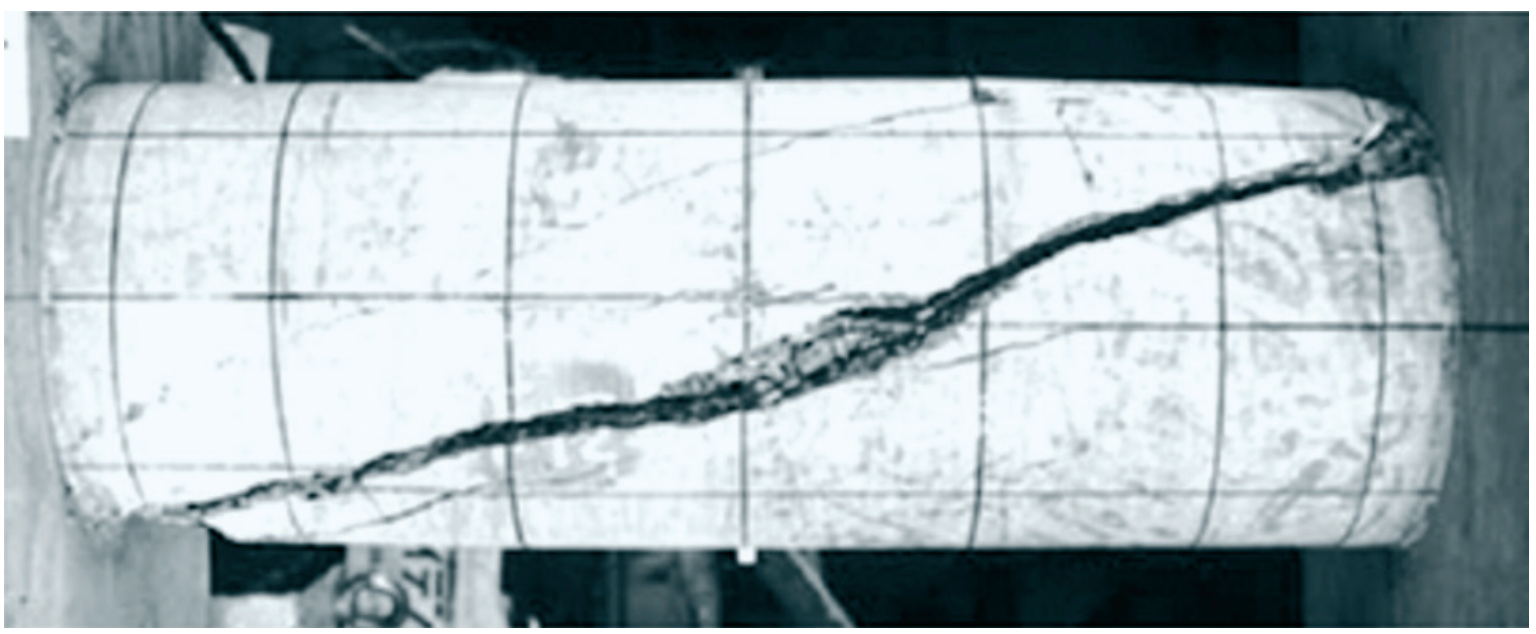


experimental results. The main idea is to find and propose parameters $\left(b_{w}\right.$ and $\left.d\right)$ that if adopted by the Brazilian Standard would lead to conservative results of shear strength when compared to the few experimental values available. At the same time compare such results using NBR 6118 [10] with results obtained using Canadian code, CSAA23.3 [9], which is based on the MCFT.

By analyzing existing codes, basically there exist two approaches for shear design of members: the first approach presents empirical and truss-based models, like for instance, ACI 318, NBR 6118 and EUROCODE 2; The second one presents mechanical based models, like CSA A23.3, ASSHTO LFRD and FIB 2010. Hence, it was chosen a representative code for each approach in order to make a comparison of their accuracy.

\section{The Modified Compression Field Theory - MCFT}

Developed initially by VECCHIO \& COLLINS [11] and afterwards by COLLINS \& MICHEL [12], the MCFT is a general model used to find the load deformation response of cracked reinforced concrete elements subjected to shear forces. This model considers equilibrium, compatibility of deformations and stress-strain relationship of the materials. Unlike other models, the MCFT considers the tension strength between the cracks. Thus, after cracked, the concrete carries shear by a field of diagonal compression and by tension stresses between the cracks, which in turn lead to smaller strains and therefore shear strength less conservative. This tension stresses at the other hand varies in magnitude from zero at the cracks to its maximum value between the cracks.

As expected, the MCFT brings a new unknown to be determined; the tension stress $\left(f_{1}\right)$, nevertheless it additionally presents two strain compatibility equations and constitutive relationships for the materials, which link stresses and strains. It is important to notice that reinforced concrete is treated as a continuous material, and consequently there is no slipping between steel and concrete, moreover compatibility relationships are expressed in terms of average strains. Another important aspect of the MCFT is that it considers that the principal stresses and principal strains have the same inclination, $\theta$. Thereby, such model makes it possible to determine the average stresses and strain for any level of load until the member collapses. The MCFT was used as the base of the general method in the 1994 CSA and continues being used in the current Canadian code. The equations of the MCFT are shown in the Figure 2.

\section{Codes and studies developed}

The design of a member subject to shear usually consists of two steps: verification of the concrete web crushing and verification of the diagonal tension. The web crushing verification establishes the maximum shear strength of a member.

\section{Figure 2 - Equations of the Modified Compression Field Theory (Adapted from COLLINS \& MICHEL (12))}

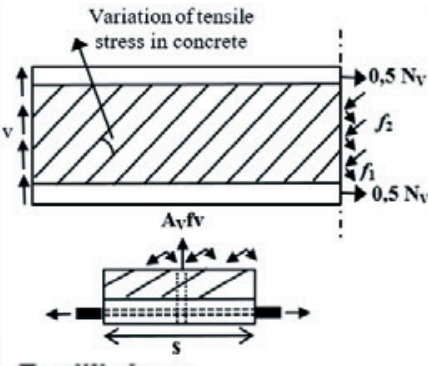

Equilibrium:

1. $f_{2}=(\tan \theta+\cot \theta) \cdot \frac{v}{b_{w} j d}-f_{1}$

2. $N_{v}=V \cot \theta-f_{1} \cdot b_{w} j d$

3. $\frac{A_{v} f_{y}}{s}=\frac{V}{j d \cdot \cot \theta}-f_{1} \cdot b_{w}$ $V=f_{1} \cdot b_{w} \cdot j d \cdot \cot \theta+\frac{f_{v} A_{v}}{s}, j d \cdot \cot \theta$
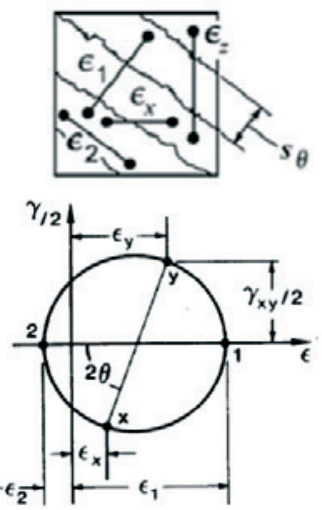

Compatibility Conditions Average Strains

4. $\tan ^{2} \theta=\frac{\epsilon_{x}+\epsilon_{2}}{\epsilon_{z}+\epsilon_{2}}$

5. $\epsilon_{1}=\epsilon_{x}+\epsilon_{z}+\epsilon_{2}$

6. $\gamma_{x z}=2\left(\epsilon_{x}+\epsilon_{2}\right) \cot \theta$

Crack Widths

7. $w=s_{\theta} \epsilon_{1}$

8. $s_{\theta}=1 /\left(\frac{\sin \theta}{s_{x}}+\frac{\cos \theta}{s_{z}}\right)$
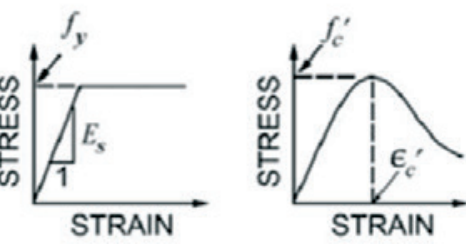

Stress-Strain Relationships:

Reinforcement

9. $f_{\mathrm{sx}}=E_{s} \epsilon_{x} \leq f_{y x}$

10. $f_{s z}=E_{s} \epsilon_{z} \leq f_{y z}$

Concrete:

11. $f_{2}=\frac{f_{c}^{\prime}}{0.8+170 \epsilon_{1}}\left[2 \frac{\epsilon_{2}}{\epsilon_{c}{ }^{\prime}}-\left(\frac{\epsilon_{2}}{\epsilon_{c}{ }^{\prime}}\right)^{2}\right]$

12. $f_{1}=0.33 \sqrt{f_{c}^{\prime}} /\left(1+\sqrt{500 \epsilon_{1}}\right) \mathrm{MPa}$

Shear Stress on Crack

13. $v_{c i} \leq \frac{0.18 \sqrt{f_{c}^{\prime}}}{0.31+\frac{24 w}{a_{g}+16}} \quad \mathrm{MPa}, \mathrm{mm}$ 
The diagonal tension generally determines the actual shear strength of a member, which should be smaller them the shear strength determined by the web crushing verification. Such resistance is composed by the concrete contribution $\left(V_{c}\right)$ plus the shear reinforcement contribution $\left(V_{s}\right)$. The formulation proposed for $V_{s}$ is uniform among most of the codes. The main challenge lies on determining the contribution of the concrete $V_{c}$.

\subsection{Shear strength according to NBR 6118}

This study only considered the model I of the Brazilian standard, which considers that the inclination $(\theta)$ is equal to $45^{\circ}$, differently from the model II, which allows the designer choose any value among $30^{\circ}$ and $45^{\circ}$. The Model I was adopted due to its simplicity involving less parameters and also due to the lack of experimental data.

According to NBR 6118 [10], the design shear force $\left(V_{\mathrm{sd}}\right)$ must be smaller than the design shear resistance concerning the collapse by diagonal tension $\left(V_{\mathrm{Rd} 3}\right)$ and also smaller than the shear resistance concerning the collapse of the compressed diagonals of concrete $\left(V_{\mathrm{Rd} 2}\right)$.

The shear resistance regarding the collapse by diagonal tension $\left(V_{\mathrm{Rd} 3}\right)$ is equal to the sum between the shear resistance provided by the shear reinforcement $\left(V_{s}\right)$ and the strength provided by the complementary mechanism $\left(V_{c}\right)$. For members subject to bending and compression, the complementary mechanism is given by:

$$
V_{c}=V_{c 0} \cdot\left(1+\frac{M_{0}}{M_{s d, \text { max }}}\right) \leq 2 V_{c 0}
$$

Where $V_{c 0}$ is the concrete contribution for members subjected to pure bending, or combined tension and bending with neutral axis through the cross section, and is given by:

$$
V_{c 0}=0,6 f_{d d} b_{w} d
$$

NBR 6118 [10] considers the influence of the compression force on shear strength of a member by adding the term between brackets in Equation (1), where: $M_{0}$ is the value of the bending moment that annuls the compression stress on the edge of the section (tensioned by $M_{\text {sd, max }}$ ), caused by normal forces of different origins with concomitant $V_{\mathrm{sd}} ; M_{\mathrm{sd}, \max }$ is the maximum bending moment within the analyzed portion; $f_{\text {cdt }}$ is the design shear strength of concrete. One may note that the larger the compressive force is, the larger will be $M_{0}$, and as consequence the concrete's contribution will increase.

Concerning the verification of the web crushing, considering vertical stirrups, the shear strength $\left(V_{\mathrm{Rd} 2}\right)$ will be given by:

$$
V_{R d 2}=0,27 \cdot \alpha_{v 2} \cdot f_{c d} \cdot b_{w} \cdot d
$$

Here $\alpha_{v 2}$ is a reduction factor of concrete design resistance; $f_{c d}$ is the design compressive strength of concrete; and $b_{w}$ is effective web width.

It is important to notice that the Brazilian standard does not specifically mention circular cross section, neither hollow nor solid.

\subsection{Shear strength according to CSA A23.3}

According to the Canadian standard, regions of members, where it is reasonable to assume that the plane sections remain plane, should be designed to shear using both methods based on MCFT or strut-and-tie models. Thus, beams, columns and walls are typically designed using the "engineering beam theory", which assumes the shear stresses are distributed over the height of the member.

Differently from the Brazilian standard, CSA A23.3 [9] establishes parameters for circular cross sections. In such cases the effective web width $\left(b_{w}\right)$ should be taken as the diameter of the section, whereas the depth $(d)$ need not be less than $0,8 \mathrm{~h}$ for prestressed members with circular sections.

For the Canadian standard, $V_{c}$ is considered as the concrete's ability to transmit shear stress through the cracks by the action of aggregates interlocking. Thus the shear strength provided by the concrete will be given by:

$$
V_{c}=\lambda \varphi \beta \cdot \sqrt{f_{c}^{\prime}} \cdot b_{w} \cdot d_{v}
$$

where $\beta . f^{\prime}{ }_{c}^{1 / 2}$ is the shear stress (see Figure 2), also called aggregate interlock, $\varphi$ is the resistance factor for concrete and $\lambda$ is a factor to account for low-density concrete. However CSA A23.3 [9] limits the specified compressive strength of concrete $\left(f_{c}^{\prime}\right)$ to 64 $\mathrm{MPa}$ in order consider that the aggregate interlock is less effective in high strength concretes.

The most general procedure of the Canadian standard for determining the factor accounting for shear resistance of cracked concrete $(\beta)$ and the inclination $(\theta)$ takes into account the axial force $(N)$, prestressing $\left(V_{\mathrm{p}}\right)$, crack spacing $\left(s_{\mathrm{ze}}\right)$, longitudinal reinforcement ratio, and ratio between shear force and bending moment. The equations for determining $\beta$ and $\theta$ according to the general method are given below:

$$
\beta=\left(\frac{0,40}{1+1500 \varepsilon_{x}} \cdot \frac{1300}{1000+s_{z e}}\right)
$$

$$
\theta=29+7000 \varepsilon_{x}
$$

Where $\varepsilon_{\mathrm{x}}$ is the longitudinal strain and $s_{\mathrm{ze}}$ is the equivalent crack spacing parameter dependent on crack control characteristics of longitudinal reinforcement.

For sections containing at least the minimum transverse reinforcement, the equivalent space of crack, $s_{\mathrm{ze}}$, can be adopted as 
$300 \mathrm{~mm}$, or alternatively by Equation (7), where $s_{z}$ is the crack spacing parameter, adopted as the effective shear depth, $d_{\mathrm{v}}$, or as the maximum distance between layers of distributed longitudinal reinforcement, whichever is less; and $a_{\mathrm{g}}$ is the specified nominal maximum size of the coarse aggregate.

$$
s_{z e}=\frac{35 s_{z}}{15+a_{g}} \geq 0,85 s_{z}
$$

CSAA23.3 [9] considers $\varepsilon_{\mathrm{x}}$ at the mid-depth of the cross-section by conservatively approximating $\varepsilon_{\mathrm{x}}$ to half of the strain at the bending tension reinforcement. Thus the longitudinal strain is given, conservatively, by the following equation:

$$
\varepsilon_{x}=\frac{\frac{M_{f}}{d_{v}}+V_{f}-V_{p}+0,5 N_{f}-A_{p} \cdot f_{p 0}}{2 \cdot\left(A_{s} \cdot E_{s}+A_{p} \cdot E_{p}\right)}
$$

where $M_{f}$ is the bending moment due to design loads; $N_{f}$ is the design axial loading, normal to the cross section, including tension effects due to creep and shrinkage (adopted as positive for tension and negative for compression); $A_{\mathrm{p}}$ is the area of prestressing reinforcement on the tension side of the member; $E_{\mathrm{p}}$ is the modulus of elasticity of prestressing tendons; $A_{\mathrm{s}}$ is the area of non-prestressed longitudinal reinforcement; $E_{\mathrm{s}}$ is modulus of elasticity of non-prestressed longitudinal reinforcement; and $V_{p}$ is the factored vertical component of the effective prestressing force, $V_{f}$ is the factored shear force, and $f_{p 0}$ is the stress in prestressed tendons when strain in the surrounding concrete is zero.

One may notice that the bigger the compressive force, the smaller the longitudinal strain, and as consequence $V_{c}$ will be larger because it is a function of $\beta$.

\subsection{Other codes and studies that deal with hollow circular and solid circular cross sections}

Traditional standards generally propose empirical formulas to evaluate the shear force resisted by complementary mechanisms $\left(V_{c}\right)$. Such formulations are usually taken from tests on beams with rectangular cross sections, and the results are extrapolated to members with any cross section. The same holds true for analytic formulas proposed to assess shear force resisted by the stirrups $\left(V_{\mathrm{s}}\right)$. Parameters established by codes and studies that somehow deal with circular cross sections are discussed below.

The American standard $\mathrm{ACl} 318$ [1], as mentioned previously, presents a simplified method for calculating the shear strength of members with circular cross sections. It is recommended a replacement of the circular cross-section by an equivalent rectangular cross section with the effective web width $\left(b_{\mathrm{w}}\right)$ equal to the diameter, $D$; and effective height $(d)$ equal to 0,8 . $D$.

The American standard, AASHTO LRFD [8] specifies that for circular sections, such as prestressed concrete columns or piles, $d_{v}$ may be adopted as $0,9 d_{\mathrm{e}}$, as can be seen in the Figure 3, where $d$ is the effective depth from extreme compression fiber to the centroid of the tensile force in the tensile reinforcement, $D_{r}$ is the diameter of the circle passing through the centers of the longitudinal reinforcement and $d_{v}$ is the effective shear depth.

$$
d_{e}=\frac{D}{2}+\frac{D_{r}}{\pi}
$$

$\mathrm{ACI} 371 \mathrm{R}$ [13] which deals with analysis, design and construction of concrete-pedestal water towers, considers that the shear forces caused by wind and earthquakes are resisted by two equivalent shear walls parallel to the direction of the applied load. The length of each shear wall cannot exceed $0,78 d_{w}$, where $d_{w}$ is the mean diameter of the concrete cylinder as can be seen in Figure 4.

Although the EUROCODE 2 [14] does not treat any type of circular sections, it considers an important aspect not addressed by any other codes presented in this study. The European standard considers the degrading effect of shear strength due to high compressive stresses. Such behavior is included in the resistance check of the compressed diagonals, $V_{\mathrm{Rd} \text {, max }}$, by the inclusion of the coefficient $\alpha_{c w}$ which takes account of the state of the stress in the compression chord. Hence, when $\sigma_{N} / f_{c d}$ is equal to 0,6 ; $\alpha_{c w}$ is taken as 1 , and the upper limit for the enhancement due to compression force is achieved. For any ratio $\sigma_{N} / f_{\text {cd }}$ larger than 0,6 and smaller than 1 , linear interpolation between this solution and zero must be used to determine $\alpha_{c w^{*}}$. Here $\sigma_{N}$ is the compressive stress in the concrete at the centroid axis, due to normal and prestressing forces.

REGIS [15] presented an experimental study where he proposed some modifications to a computational program in order to include hollow circular cross sections in the analysis of shear strength of members subject to shear, bending and compression forces. According REGIS [15], the failure mechanisms of members with hollow circular cross sections differ substantially from mechanisms of solid circular sections, due to the fact that the compression struts have curved axis. Consequently they undergo a more unfavorable stress state.

\section{Figure 3 - Parameters bw, dv and de for circular cross sections according to the AASHTO LFRD(8)}

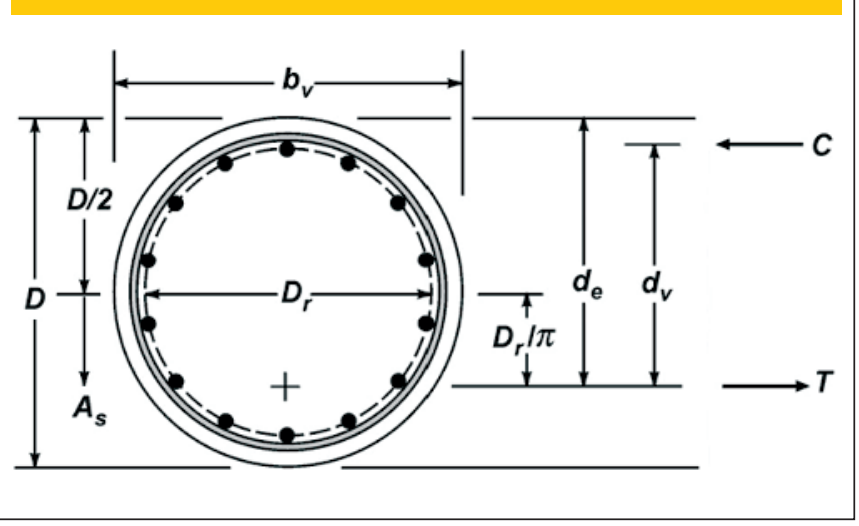




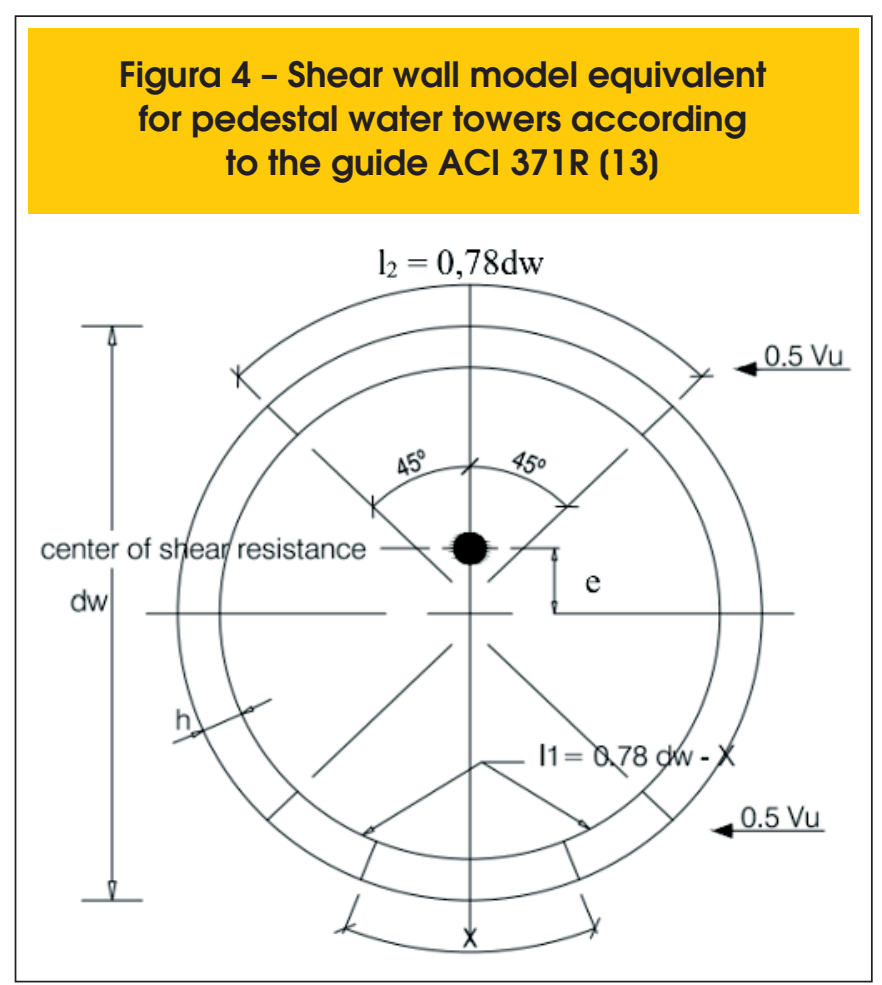

RUIZ \& TURMO [16] aiming to study the rupture mechanisms of cylindrical and hollow bridges piers, subjected to shear forces, proposed an approximation of the hollow section to two equivalent webs, each one with an effective width $\left(b_{w}\right)$ equal to the thickness of the hollow section $(t)$ and the depth $(d)$ equal to $90 \%$ of half the cylinder's outer perimeter.

JENSEN \& HOANG [2] presented a model using a plasticity approximation to determine the shear strength of pillars and piles of bridges, loaded with combinations of shear and normal forces. Depending on the normal compressive force, it was assumed that the shear strength of a member with hollow circular cross section is determined by the shear failure in a cracked concrete or in an uncracked concrete. Thus, it was possible to calculate the beneficial effect on the shear strength due to axial compression. They found very similar results in comparison to the experimental data taken from the literature.

Recently VÖLGYI et al.[4] presented an experimental study where it was examined the ultimate shear resistance, propagation of characteristic crack and shape of the rupture sections as function of the wall thickness $(t)$, of the longitudinal and transverse reinforcement amount, of the shear span (a), and of the axial force $(N)$. The test results were used to verify a calculation model presented by VÖLGYI \& WINDISCH [17]. The proposed method is based on a balance of internal forces along the collapse section. It proposes an adjustment in the calculation of the stirrups resistance, and an analysis of concrete contribution in the compression zone as a function of the distance between the end of the crack and the loading point $\left(I_{c}\right)$, where the inclination of the central portion of the collapse section was adopted as being $45^{\circ}$ (see Figure 5).

VÖLGYI et al. [4] concluded that the strength of reinforced concrete members with hollow circular cross sections, increases with the increasing of the wall thickness ( $t$ ), with the amount of longitudinal and transverse reinforcement, with the level of prestress applied, and with the reduction of the shear span (for a/D smaller than 3.5). It was also observed that the strength of members without stirrups has proved to be greater than the shear force at the appearance of the first shear crack.

\subsection{Analysis of the existing codes and studies - proposition of parameters $b_{w}$ and $d$}

Although the ACI 318[1], the CSA A 23.3[9] and the AASHTO LFRD[8] present some parameters that allow the determination of the shear strength of members with solid circular cross sections, the only one that somehow deal with hollow circular cross sections, subjected to shear forces, is ACI 371R [13] which is applied to concrete pedestal water towers. According to this report, water towers are regarded as two equivalent shear walls and parallel to the direction of the applied load.

Thus, adopting the analysis done by ACI 371R [13] report, $b_{\mathrm{w}}$ was considered as being twice the thickness of the member (2.t). With regard to the depth $(d)$, after some analyses of the parameters suggested by the above mentioned codes, it was adopted the values suggested by CSAA23.3 [9] and ACI 318[1], i.e. $d$ is equal to $0,8 D$. Such analyses were performed by calculating the shear strength of some specimens, using the formulation proposed by both Brazilian and Canadian codes, replacing only $b_{\mathrm{w}}$ and $d$ by the suggested parameters.

Concerning the degradation effect on the shear strength of members subjected to very high compression forces, it was adopted the approach suggested by the EUROCODE 2 [14]. However, since the Brazilian code already considers the enhancement effect of the shear strength of members subject to compression forces, the formulation proposed by the EUROCODE 2 [14] was adjusted in order to take into account only the degradation effect. Hence, we propose including the coefficient $\alpha_{c w}$ to the analysis of the shear strength to guard against possible detrimental effects on web crushing of high normal stresses.

$$
V_{R d 2}=0,27 \cdot \alpha_{v 2} \cdot \alpha_{a v} \cdot f_{d d} \cdot b_{w} \cdot d
$$

Figure 5 - Model proposed for the compression zone according to VÖLGYI \& WINDISCH, (17)

\section{Side view of the test specimen}

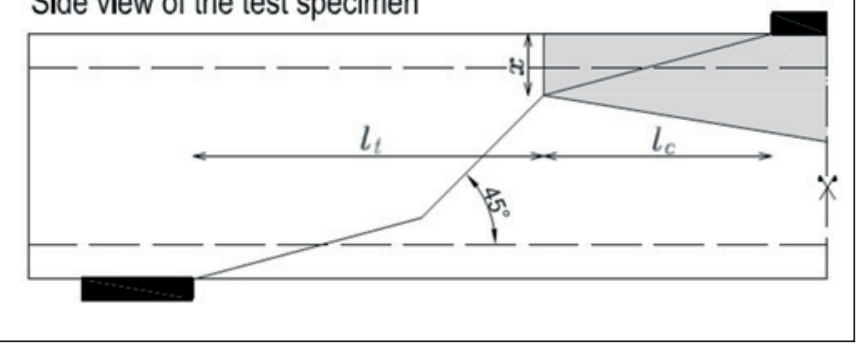


Where,

$\alpha_{c \nu}=1,00$ if $0 \leq \frac{\sigma_{N}}{f_{c d}} \leq 0,6$

$\alpha_{c \nu}=2,5\left(1-\frac{\sigma_{N}}{f_{c d}}\right)$ if $0,6<\frac{\sigma_{N}}{f_{c d}}<1,0$

Here $\sigma_{\mathrm{N}}$ is the compressive stress in the concrete at the centroidal axis due to axial load and/or prestress.

\section{Experimental data base}

To evaluate the calculation procedure established in the previous section of this paper, results of 79 tests have been collected. These tests are the only published tests found by the authors.

The specimens presented by REGIS [15] were tested as simply supported members subjected to two symmetric shear forces, and axial compression applied by means of a hydraulic jack. According to REGIS [15], all the members presented bending-shear failure.

The specimens tested by RUIZ \& TURMO [16] were also simply supported, however without axial compression. The concentrated load was applied by means of a hydraulic jack at the mid-length of the beam. According to RUIZ \& TURMO [16] all the members presented bending-shear failure.

The data presented by JENSEN \& HOANG [2], was actually based on tests carried by KISHIDA et al [3]. The level of axial compression $\left(\sigma_{N}\right.$ $/ f_{c}$ ) varied between zero $(0)$ and 0,33 ; with axial compression applied either as combination of prestressing and external normal force, or as prestressing only. JENSEN \& HOANG [2] published only members that presented bending-shear failure. In this study, it was omitted the specimens with central length of $600 \mathrm{~mm}$, as well as some members with prestressing and/or axial compression for lack of precise data. Figure 6 shows the test setup performed by KISHIDA et al [3].

In the study developed by VÖLGYI et al. [4], they tested 45 specimens, from which 27 were not subjected to any type of axial compression, and the remainders were subjected to prestressing. The tests were performed by making an equivalent scheme of a horizontal beam, simply supported, subjected to a concentrated load, applied by means of a hydraulic jack, at variable distances $(625,825$ and $975 \mathrm{~mm}$ ) from the center of one of the supports. According to

\section{Figure 6 - Test setup reproduced from KISHIDA et al (3)}

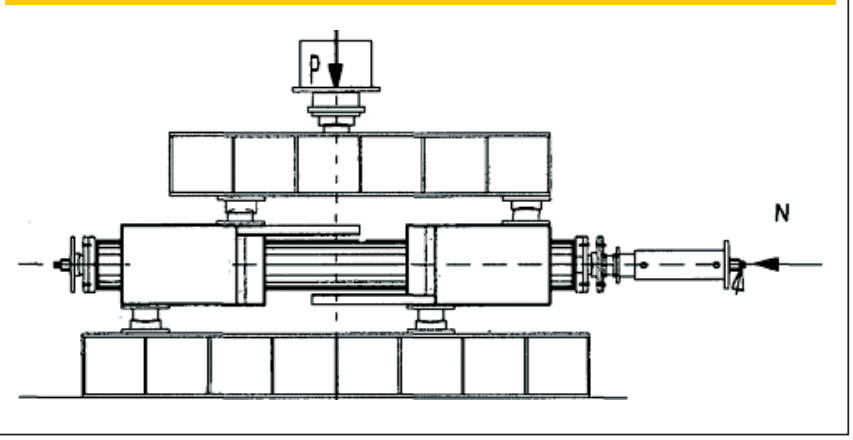

VÖLGYI et al. [4] all the members presented bending-shear failure. Figure 7 shows the test setup performed by VÖLGYI et al. [4]; and Tables 1 and 2 presents the collected experimental data base where: $\mathrm{D}$ and $\mathrm{D}_{0}$ are the external and internal diameter of piles respectively; $\varnothing_{t}$ is the diameter of the transverse reinforcement; $\varnothing$, is the diameter of the longitudinal reinforcement; $s$ is the spacing of headed shear reinforcement or stirrups, $t$ is the wall thickness; $\sigma_{N}$ is the compressive stress in the concrete at the centroidal axis, $f_{y}$ is the specified yield strength of non-prestressed reinforcement, $V_{\text {exp }}^{y}$ is the shear strength obtained experimentally through the test results, $V_{R d 3}$ and $V r$ is the shear strength calculated through the Brazilian and Canadian codes respectively.

\section{Results and analysis}

\subsection{Influence of axial compression force on shear resistance}

Observing the experimental data base presented in Table 1 and 2, it is possible to notice that as the axial compressive forces increase so does the shear strength. Such behavior was observed either in members with stirrups as well as members without shear reinforcement.

Figure 7 - Test setup reproduced from VÖLGY et al (4)
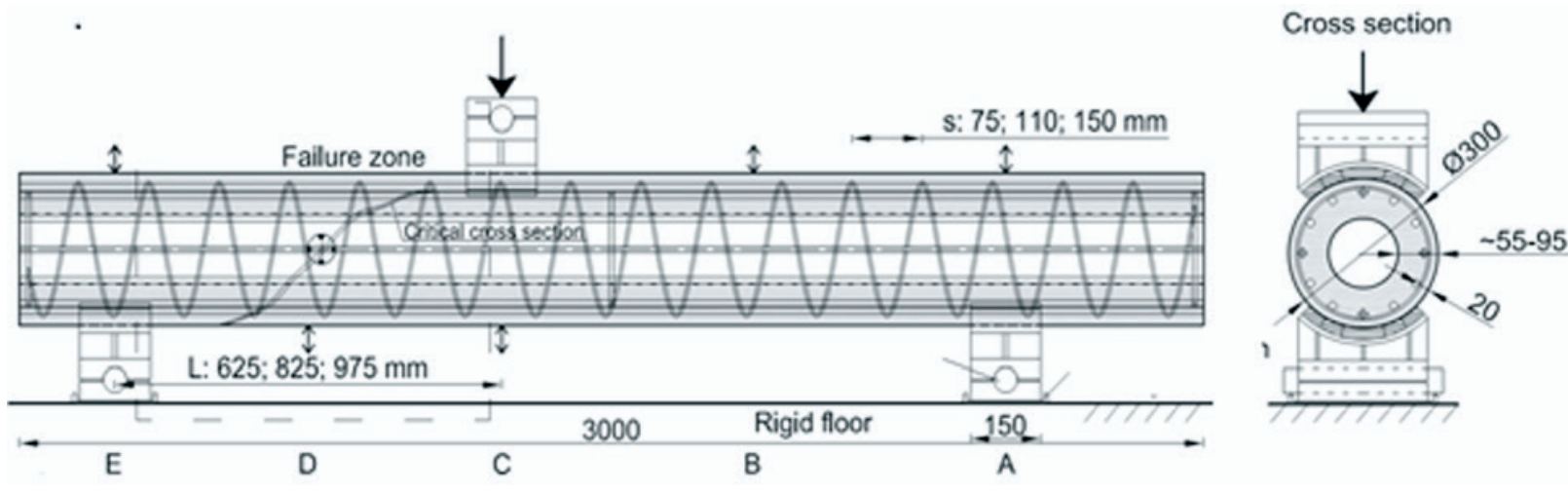
As example, one may point out the specimens JP3-40-15-70 and JP3-40-15-105, presented by JENSEN \& HOANG, [2] which have same characteristics except the normal compressive stresses which increase gradually, and as consequence the shear resistance also increases. In some cases the increase in normal stresses compensates for the decrease in longitudinal reinforcement as can be seen from the results of specimens JP3-40-15- 70 and JP3-80-15-35.

\subsection{Influence of wall thickness on shear resistance}

By comparing the members 55-16-0-825 and 90-16-0-825 of Table 2 which have the same characteristics, except for the wall thickness, it is possible to notice that the shear resistance of the member $90-16-0-825$ is about $57 \%$ higher than of member $55-16-0-825$, whose thickness is $40 \%$ smaller. The same holds true for the members 55-12-0-625 and 90-12-0-625.

In general it is possible to state that: as the wall thickness increases, so does the shear strength. Greater wall thickness results greater effective web width $\left(b_{\mathrm{w}}\right)$, which in turn leads to larger shear area of aggregate interlock, therefore there is a greater contribution of the concrete for shear resistance.

\subsection{Influence of the shear span ratio (a/D) on the shear resistance}

Observing the results presented by VÖLGYI et al [4] in Table 2 one may see that: as shear span ratio $(a / D)$ decreases, the shear strength increases. In the case of specimens 55-12-150-625 and 55$16-150-975$ the reduction in longitudinal reinforcement is more than compensated by the reduction of shear span (a) and larger shear strength is obtained. Similarly in the case of specimens 90-16-150F2-975 and 90-16-150-F1-625 the decrease in normal stresses is more than compensated by the decrease in the shear span.

\subsection{Comparison of test results with shear resistance computed using the Brazilian and Canadian codes}

Using the experimental data base, and adopting the effective width



$\left(b_{\mathrm{w}}=2 . t\right)$ and depth $((d=0,8 \mathrm{D}))$ as previously proposed in the section 4 , the shear resistance of each member was calculated using the provisions of NBR 6118 [10] and CSA A23.3 [9], without the safety factors.

The last two columns of Table 1 and 2 present the results using both Brazilian and Canadian codes.

\subsubsection{Results using CSA A23.3}

Regarding the results obtained using the Canadian Code, it was observed that, similarly to the analysis of the experimental results, increasing normal compressive stress, results in an increase in shear strength. According to CSA A23.3 [9], as the normal compression stress increases, the longitudinal strain decreases, causing an increasing in $\beta$ and consequently in $V_{c}$. At the same time there is also a decrease in $\theta$, which in turn causes an increase in the shear strength supported by the stirrups $\left(V_{s}\right)$.

It was also possible to verify that as shear span (a) decreases, the shear strength of the members increase, similarly to what was observed from the experimental data. Such behavior is considered by the Canadian Standard through the influence of the bending moment of the critical section, in the calculation of the longitudinal strain. Regarding the influence of the wall thickness $(t)$, it was observed the same behavior observed in the experimental results, i.e, as the wall thickness increases, the shear strength also increases. The graph of Figure 8 presents the results of Table 1 and Table 2. It can be seen that all the shear strength calculated using the Canadian Standard are on the safe side. The average value of $V_{r}$ I $V_{\text {exp }}$ was 0,62 with a standard deviation of 0,077 .

\subsubsection{Results using NBR 6118}

Regarding the results using the model I of NBR 6118 [10], one may notice that: as compressive stress increases shear strength also increases. Such behavior is modeled through the decompression bending moment $M_{0}$. Thus, as compression stresses increase, so does $M_{0}$, therefore the complementary mechanism $\left(V_{c}\right)$ increases. Differently from the Canadian code, as the compressive stress increases there is no increasing of the stirrups contribution $\left(V_{\mathrm{s}}\right)$, due

\section{Figure 9 - Ratio between the Shear strength calculated according to NBR 6118 and experimental results, as a function of the applied compressive stress}

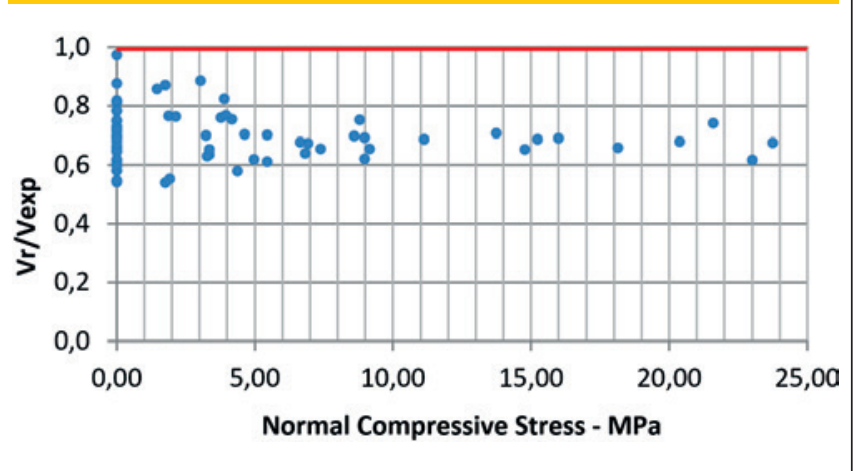


to the fact that the model I considers a fixed angle, $\theta$, of $45^{\circ}$. It was also observed when analyzing Table 2, that for elements that are not subject to compressive stress, the change in the shear span (a) does not influence the shear strength of the members. However for the elements subjected to combined bending and compression, as the shear span (a) decreases, occurs a decrease

Table 1 - Data collected form REGIS (15), RUIZ \& TURMO (16) and JENSEN \& HOANG (10)

\begin{tabular}{|c|c|c|c|c|c|c|c|c|c|c|c|c|c|}
\hline Peças & $\begin{array}{c}\mathrm{D} \\
\mathrm{mm}\end{array}$ & $\begin{array}{l}\mathrm{D}_{0} \\
\mathrm{~mm}\end{array}$ & $t / D$ & $\begin{array}{l}\mathrm{N}^{\circ} \text { of } \\
\text { long. } \\
\text { bars }\end{array}$ & $\begin{array}{c}\emptyset_{f} \\
\mathrm{~mm}\end{array}$ & $\begin{array}{c}\emptyset_{1} \\
\mathrm{~mm}\end{array}$ & $\begin{array}{c}\mathrm{s} \\
\mathrm{mm}\end{array}$ & $\begin{array}{c}f_{c} \\
M P a\end{array}$ & $\begin{array}{c}f_{y} \\
M P a\end{array}$ & $\sigma_{N} / f_{c}$ & $\begin{array}{l}V_{\text {exp }} \\
(k N)\end{array}$ & $\begin{array}{l}V_{\text {Rd3 }} \\
\text { KN } \\
\text { NBR } \\
\end{array}$ & $\begin{array}{l}V_{r} \\
k N \\
\text { CSA } \\
\end{array}$ \\
\hline \multicolumn{14}{|c|}{ REGIS, 1990 (15) } \\
\hline $\mathrm{V}_{\mathrm{Al}}$ & 300 & 180 & 0,2 & 12 & - & 16 & - & 34,2 & - & 0,25 & 55 & 38,23 & 43,51 \\
\hline$V_{A 2}$ & 300 & 180 & 0,2 & 12 & - & 16 & - & 32,7 & - & 0 & 83 & 58,29 & 59,35 \\
\hline $\mathrm{V}_{\mathrm{B} 1}$ & 300 & 180 & 0,2 & 12 & 6,35 & 16 & 150 & 35,5 & 600 & 0,25 & 130 & 84,80 & 106,96 \\
\hline $\mathrm{V}_{\mathrm{B} 2}$ & 300 & 180 & 0,2 & 12 & 6,35 & 16 & 150 & 37 & 600 & 0 & 158 & 96,77 & 119,94 \\
\hline \multicolumn{14}{|c|}{ RUIZ \& TURMO, 2004 (16) } \\
\hline $\mathrm{V}_{\mathrm{cl}}$ & 600 & 400 & 0,17 & 12 & 6 & 20 & 300 & 31,93 & 500 & - & 233,20 & 162,49 & 153,0 \\
\hline $\mathrm{V}_{\mathrm{c} 2}$ & 600 & 400 & 0,17 & 12 & 6 & 20 & 300 & 31,93 & 500 & - & 239,20 & 162,49 & 153,0 \\
\hline$V_{A 1}$ & 600 & 400 & 0,17 & 12 & 6 & 20 & 300 & 24,72 & 500 & - & 236,70 & 143,36 & 144,9 \\
\hline $\mathrm{V}_{\mathrm{A} 2}$ & 600 & 400 & 0,17 & 12 & 6 & 20 & 300 & 24,72 & 500 & - & 216,70 & 143,36 & 144,9 \\
\hline \multicolumn{14}{|c|}{ JENSEN \& HOANG, 2010(2) } \\
\hline JP3401570 & 300 & 180 & 0,2 & 6 & 3,2 & 7,1 & 50 & 93,5 & 539 & 0,194 & 259,22 & 170,93 & 147,91 \\
\hline JP34015105 & 300 & 180 & 0,2 & 6 & 3,2 & 7,1 & 50 & 93,5 & 539 & 0,274 & 300,39 & 186,60 & 159,99 \\
\hline JP38015 & 300 & 180 & 0,2 & 8 & 3,2 & 9,0 & 50 & 93,5 & 539 & 0,074 & 214,43 & 144,34 & 137,45 \\
\hline JP3801535 & 300 & 180 & 0,2 & 8 & 3,2 & 9,0 & 50 & 93,5 & 539 & 0,158 & 250,62 & 163,60 & 147,55 \\
\hline JP3001535 & 300 & 180 & 0,2 & 10 & 3,2 & 9,0 & 50 & 93,5 & 539 & 0,094 & 198,60 & 149,49 & 141,23 \\
\hline JP310015 & 300 & 180 & 0,2 & 10 & 3,2 & 9,0 & 50 & 93,5 & 539 & 0,096 & 216,69 & 149,93 & 141,90 \\
\hline JP3001570 & 300 & 180 & 0,2 & 10 & 3,2 & 9,0 & 50 & 93,5 & 539 & 0,163 & 239,77 & 164,71 & 149,72 \\
\hline JP31001535 & 300 & 180 & 0,2 & 10 & 3,2 & 9,0 & 50 & 93,5 & 539 & 0,171 & 240,67 & 166,38 & 150,77 \\
\hline JP30015105 & 300 & 180 & 0,2 & 10 & 3,2 & 9,0 & 50 & 93,5 & 539 & 0,231 & 241,12 & 178,82 & 159,80 \\
\hline JP6401570 & 300 & 210 & 0,15 & 6 & 2,9 & 7,2 & 55 & 93,5 & 589 & 0,246 & 228,92 & 141,49 & 126,28 \\
\hline JP64015105 & 300 & 210 & 0,15 & 6 & 2,9 & 7,2 & 55 & 93,5 & 589 & 0,333 & 244,78 & 153,82 & 138,10 \\
\hline JP68015 & 300 & 210 & 0,15 & 8 & 2,9 & 9,0 & 55 & 93,5 & 589 & 0,073 & 170,88 & 109,56 & 107,28 \\
\hline JP6801570 & 300 & 210 & 0,15 & 8 & 2,9 & 9,0 & 55 & 93,5 & 589 & 0,288 & 248,02 & 147,60 & 129,80 \\
\hline JP610015 & 300 & 210 & 0,15 & 10 & 2,9 & 9,0 & 55 & 93,5 & 589 & 0,096 & 183,85 & 114,38 & 110,47 \\
\hline JP6001570 & 300 & 210 & 0,15 & 10 & 2,9 & 9,0 & 55 & 93,5 & 589 & 0,218 & 201,88 & 137,16 & 122,57 \\
\hline JP60015105 & 300 & 210 & 0,15 & 10 & 2,9 & 9,0 & 55 & 93,5 & 589 & 0,306 & 228,56 & 150,16 & 133,30 \\
\hline JP61001570 & 300 & 210 & 0,15 & 10 & 2,9 & 9,0 & 55 & 93,5 & 589 & 0,309 & 211,61 & 150,60 & 133,70 \\
\hline JP610015105 & 300 & 210 & 0,15 & 10 & 2,9 & 9,0 & 55 & 93,5 & 589 & 0,396 & 228,56 & 161,93 & 146,50 \\
\hline JP910015 & 300 & 220 & 0,133 & 8 & 2,9 & 9,0 & 50 & 93,5 & 589 & 0,098 & 164,67 & 107,86 & 106,21 \\
\hline JP98015 & 300 & 220 & 0,133 & 10 & 2,9 & 7,1 & 50 & 93,5 & 589 & 0,079 & 159,44 & 104,37 & 106,93 \\
\hline JP12 8015 & 300 & 225 & 0,125 & 6 & 2,9 & 9,0 & 45 & 93,5 & 589 & 0,071 & 150,91 & 102,22 & 104,19 \\
\hline JP12401535 & 300 & 225 & 0,125 & 6 & 2,9 & 7,2 & 45 & 93,5 & 589 & 0,147 & 162,36 & 114,92 & 109,71 \\
\hline JP12401570 & 300 & 225 & 0,125 & 6 & 2,9 & 7,2 & 45 & 93,5 & 589 & 0,280 & 208,74 & 132,89 & 121,60 \\
\hline JP1210015 & 300 & 225 & 0,125 & 8 & 2,9 & 9,0 & 45 & 93,5 & 589 & 0,092 & 151,91 & 105,99 & 100,84 \\
\hline JP12001570 & 300 & 225 & 0,125 & 8 & 2,9 & 9,0 & 45 & 93,5 & 589 & 0,254 & 191,74 & 129,67 & 105,00 \\
\hline JP12001535 & 300 & 225 & 0,125 & 8 & 2,9 & 9,0 & 45 & 93,5 & 589 & 0,119 & 160,81 & 110,52 & 119,00 \\
\hline
\end{tabular}


Table 2 - Data collected form VÖLGYI et al. (4)

\begin{tabular}{|c|c|c|c|c|c|c|c|c|c|c|c|c|c|c|}
\hline Peças & $\underset{\mathrm{mm}}{\mathrm{D}}$ & $\begin{array}{c}D_{0} \\
\mathrm{~mm}\end{array}$ & $t / D$ & $\begin{array}{l}\mathrm{N}^{\circ} \text { of } \\
\text { long. } \\
\text { bars }\end{array}$ & $\underset{\mathrm{mm}}{\varnothing_{\mathrm{t}}}$ & $\begin{array}{c}\emptyset_{1} \\
\mathrm{~mm}\end{array}$ & $\begin{array}{c}\mathrm{s} \\
\mathrm{mm}\end{array}$ & $\underset{\mathrm{mm}}{\mathrm{a}}$ & $\begin{array}{c}f_{c} \\
M P a\end{array}$ & $\begin{array}{c}f_{y} \\
M P a\end{array}$ & $\sigma_{\mathrm{N}} / \mathrm{f}_{\mathrm{c}}$ & $\begin{array}{l}V_{\text {exp }} \\
\text { (kN) }\end{array}$ & $\begin{array}{c}V_{\text {Rda }} \\
\text { kN } \\
\text { NBR }\end{array}$ & $\begin{array}{c}v_{r} \\
k N \\
\text { CSA }\end{array}$ \\
\hline $55-12-0-975$ & 300 & 190 & 0,19 & 12 & 12 & - & - & 975 & 72,9 & 581 & - & 68,60 & 60,16 & 40,49 \\
\hline $55-12-0-625$ & 300 & 190 & 0,19 & 12 & 12 & - & - & 625 & 72,9 & 581 & - & 105,00 & 61,22 & 46,08 \\
\hline 55-12-150-825 & 300 & 190 & 0,19 & 12 & 12 & 5 & 150 & 825 & 66,9 & 581 & - & 105,00 & 85,09 & 74,09 \\
\hline 55-12-150-625 & 300 & 190 & 0,18 & 12 & 12 & 5 & 150 & 625 & 66,9 & 581 & - & 135,00 & 83,09 & 78,25 \\
\hline $55-14-0-825$ & 300 & 190 & 0,20 & 12 & 14 & - & - & 825 & 66,1 & 581 & - & 71,70 & 58,34 & 49,47 \\
\hline $55-14-0-625$ & 300 & 190 & 0,20 & 12 & 14 & - & - & 625 & 66,9 & 581 & - & 82,80 & 59,80 & 53,29 \\
\hline 55-14-150-825 & 300 & 190 & 0,18 & 12 & 14 & 5 & 150 & 825 & 66,9 & 581 & - & 133,00 & 82,10 & 79,99 \\
\hline 55-14-150-625 & 300 & 190 & 0,20 & 12 & 14 & 5 & 150 & 625 & 66,9 & 581 & - & 162,00 & 88,08 & 87,94 \\
\hline 55-14-75-825 & 300 & 190 & 0,19 & 12 & 14 & 5 & 75 & 825 & 66,1 & 581 & - & 143,00 & 111,92 & 111,39 \\
\hline 55-14-75-789 & 300 & 190 & 0,20 & 12 & 14 & 5 & 75 & 789 & 66,1 & 581 & - & 153,50 & 114,88 & 113,69 \\
\hline $55-16-0-975$ & 300 & 190 & 0,21 & 12 & 16 & - & - & 975 & 66,9 & 581 & - & 78,00 & 63,79 & 54,30 \\
\hline $55-16-0-825$ & 300 & 190 & 0,19 & 12 & 16 & - & - & 825 & 66,9 & 581 & - & 85,40 & 56,81 & 52,26 \\
\hline 55-16-150-975 & 300 & 190 & 0,18 & 12 & 16 & 5 & 150 & 975 & 72,9 & 581 & - & 115,00 & 86,32 & 82,60 \\
\hline 55-16-150-825 & 300 & 190 & 0,20 & 12 & 16 & 5 & 150 & 825 & 72,9 & 581 & - & 140,00 & 90,54 & 87,69 \\
\hline $90-12-0-825$ & 300 & 120 & 0,32 & 12 & 12 & - & - & 825 & 70,2 & 581 & - & 95,00 & 92,63 & 59,25 \\
\hline $90-12-0-625$ & 300 & 120 & 0,31 & 12 & 12 & - & - & 625 & 70,2 & 581 & - & 158,00 & 94,69 & 62,38 \\
\hline $90-16-0-825$ & 300 & 120 & 0,32 & 12 & 16 & - & - & 825 & 66,9 & 581 & - & 134,00 & 95,68 & 74,49 \\
\hline $90-16-0-825$ & 300 & 120 & 0,33 & 12 & 16 & - & - & 825 & 66,9 & 581 & - & 135,00 & 98,67 & 76,02 \\
\hline 90-16-150-975 & 300 & 120 & 0,31 & 12 & 16 & 5 & 150 & 975 & 70,2 & 581 & - & 158,00 & 123,99 & 99,17 \\
\hline 90-16-150-825 & 300 & 120 & 0,32 & 12 & 16 & 5 & 150 & 825 & 66,9 & 581 & - & 177,00 & 123,96 & 106,20 \\
\hline $90-16-150-825$ & 300 & 120 & 0,31 & 12 & 16 & 5 & 150 & 825 & 66,9 & 581 & - & 169,00 & 121,96 & 105,32 \\
\hline 90-16-150-825 & 300 & 120 & 0,31 & 12 & 16 & 5 & 150 & 825 & 70,2 & 581 & - & 178,00 & 123,99 & 103,44 \\
\hline $90-16-150-625$ & 300 & 120 & 0,32 & 12 & 16 & 5 & 150 & 625 & 70,2 & 581 & - & 218,00 & 127,08 & 111,73 \\
\hline $90-16-150-625$ & 300 & 120 & 0,31 & 12 & 16 & 5 & 150 & 625 & 70,2 & 581 & - & 228,00 & 125,02 & 110,77 \\
\hline 90-16-110-825 & 300 & 120 & 0,30 & 12 & 16 & 5 & 110 & 825 & 66,9 & 581 & - & 187,00 & 129,26 & 115,25 \\
\hline 90-16-1 10-625 & 300 & 120 & 0,31 & 12 & 16 & 5 & 110 & 625 & 66,9 & 581 & - & 210,00 & 130,25 & 123,32 \\
\hline $90-16-75-635$ & 300 & 120 & 0,33 & 12 & 16 & 5 & 75 & 635 & 66,9 & 581 & - & 258,00 & 155,22 & 146,00 \\
\hline 55-16-150-F1-825 & 300 & 190 & 0,19 & 12 & 16 & 5 & 150 & 825 & 62,5 & 581 & 0,05 & 140,00 & 89,25 & 88,92 \\
\hline 55-16-150-F1-625 & 300 & 190 & 0,20 & 12 & 16 & 5 & 150 & 625 & 62,5 & 581 & 0,05 & 147,00 & 92,86 & 96,09 \\
\hline 55-16-75-F1-825 & 300 & 190 & 0,20 & 12 & 16 & 5 & 75 & 825 & 62,5 & 581 & 0,05 & 170,00 & 119,09 & 120,90 \\
\hline 55-16-75-F1-625 & 300 & 190 & 0,19 & 12 & 16 & 5 & 75 & 625 & 62,5 & 581 & 0,05 & 180,00 & 117,54 & 127,81 \\
\hline 90-16-150-F1-975 & 300 & 120 & 0,31 & 12 & 16 & 5 & 150 & 975 & 64,8 & 581 & 0,02 & 141,00 & 120,93 & 97,13 \\
\hline 90-16-150-F1-975 & 300 & 120 & 0,31 & 12 & 16 & 5 & 150 & 975 & 69,8 & 581 & 0,03 & 146,00 & 127,13 & 96,38 \\
\hline $90-16-150-F 1-825$ & 300 & 120 & 0,32 & 12 & 16 & 5 & 150 & 825 & 64,8 & 581 & 0,03 & 165,00 & 126,36 & 104,36 \\
\hline $90-16-150-F 1-825$ & 300 & 120 & 0,31 & 12 & 16 & 5 & 150 & 825 & 69,8 & 581 & 0,03 & 167,00 & 127,55 & 101,32 \\
\hline $90-16-150-F 1-625$ & 300 & 120 & 0,32 & 12 & 16 & 5 & 150 & 625 & 64,8 & 581 & 0,03 & 229,00 & 126,84 & 111,44 \\
\hline $90-16-150-F 1-625$ & 300 & 120 & 0,32 & 12 & 16 & 5 & 150 & 625 & 64,8 & 581 & 0,03 & 234,00 & 126,36 & 111,86 \\
\hline $90-16-150-F 2-975$ & 300 & 120 & 0,31 & 12 & 16 & 5 & 150 & 975 & 62,5 & 581 & 0,06 & 163,00 & 124,02 & 102,54 \\
\hline $90-16-150-F 2-975$ & 300 & 120 & 0,32 & 12 & 16 & 5 & 150 & 975 & 69,7 & 581 & 0,06 & 161,50 & 133,17 & 101,42 \\
\hline $90-16-150-F 2-825$ & 300 & 120 & 0,32 & 12 & 16 & 5 & 150 & 825 & 62,5 & 581 & 0,07 & 186,00 & 130,98 & 107,21 \\
\hline $90-16-150-F 2-825$ & 300 & 120 & 0,32 & 12 & 16 & 5 & 150 & 825 & 69,7 & 581 & 0,06 & 179,00 & 135,06 & 111,69 \\
\hline $90-16-150-F 2-625$ & 300 & 120 & 0,33 & 12 & 16 & 5 & 150 & 625 & 62,5 & 581 & 0,07 & 233,00 & 135,31 & 121,30 \\
\hline $90-16-150-F 2-625$ & 300 & 120 & 0,32 & 12 & 16 & 5 & 150 & 625 & 62,5 & 581 & 0,08 & 216,00 & 133,88 & 121,47 \\
\hline 90-0-150-F2-825 & 300 & 120 & 0,31 & 12 & 0 & 5 & 150 & 825 & 72,2 & 581 & 0,05 & 174,00 & 133,69 & 89,13 \\
\hline 90-0-150-F2-975 & 300 & 120 & 0,30 & 12 & 0 & 5 & 150 & 975 & 72,2 & 581 & 0,04 & 145,00 & 128,55 & 81,59 \\
\hline
\end{tabular}


in the maximum design bending moment, therefore increasing concrete resistance $\left(V_{c}\right)$.

Concerning the influence of the wall thickness $(t)$, NBR 6118 [10] formulation reproduces the observed effect of increase of shear strength with wall thickness

The graph of Figure 9 presents the results of Table 1 and Table 2. It can be seen that for all members, the shear strength computed using the model I of NBR 6118[10] are safe. The average value of $V_{r} / V_{\text {exp }}$ is 0,69 with standard deviation of 0,084 .

Thus, it can be seen that the shear strength computed using the Brazilian Standard presents values closer to the experimental results than the shear strength calculated using the Canadian Standard. However the standard deviation of $V_{\mathrm{r}} / V_{\text {exp }}$ computed using NBR 6118 is higher.

\section{Suggested procedure for hollow circular cross sections - NBR 6118}

Finally, adopting the parameters proposed in item 4.4 , it is possible to present a simple procedure that allows designers to compute safe shear strength for members with hollow circular cross sections, subjected to shear, bending and compressive axial forces. The procedure summarized below is based on model I of NBR 6118 provisions, and is valid for $0,125<t / h<0,33$.

Effective web width: $b_{w}=2 \cdot t$ ( $t$ is the thickness of the section wall) Depth: $d=0,8 D$ ( $D$ is the external diameter of the cross section)

Factored shear strength: $V_{S d} \leq V_{R d 3}=V_{c}+V_{s}$

Maximum Shear strength: $V_{\mathrm{Rd} 2}=0,27 \cdot \alpha_{v 2} \cdot \alpha_{c \nu} \cdot f_{c d} \cdot b_{w} \cdot d$

Where, $\alpha_{c v}=1$ if $0 \leq v \leq 0,6$

$\alpha_{c \nu}=2,5 \cdot(1-v)$ if $0,6<v<1$

$v=\frac{N_{d}}{A_{c} \cdot f_{c d}}$

$\alpha_{v 2}=1-\frac{f_{c k}}{250}$

Shear strength carried by concrete $\left(V_{c}\right)$

For simple bending:

$V_{c}=V_{c 0}=0,6 \cdot f_{c d} \cdot b_{w} \cdot d$

For combined bending and axial compression:

$V_{c}=V_{c 0} \cdot\left(1+\frac{M_{0}}{M_{S d, \text { max }}}\right) \leq 2 V_{c 0}$

Shear strength carried by the shear reinforcement

$V_{s w}=\left(\frac{A_{s w}}{s}\right) \cdot 0,9 d \cdot f_{y w d} \cdot(\sin \alpha+\cos \alpha)$ where $f_{y w d} \leq 435 \mathrm{MPa}$

\section{Conclusions}

Although there are few experimental data available in the literature, it was possible to carry out the necessary analyses through the 79 tests found. Thus, taking into account the existing codes and literature, and the results obtained in this study, it is possible make the conclusions below.

The codes analyzed for determining the shear strength do not specifically cover members with hollow circular cross sections;

Adopting $b_{w}$ as $2 . t$ and $d$ as $0,8 . D$ and using the provisions of the Brazilian and Canadian codes to calculate the shear strength for all tests found in the literature, the shear strength calculated presented safe results for specimens with $0,125 \leq t / h \leq 0,33$;

Shear strength increases by raising the axial compression force, the wall thickness $(t)$, and by decreasing the shear span (a). However, excessive axial compressive stresses may be detrimental to shear strength;

Both standards A23.3-04 and NBR 6118 do not consider the shear strength deterioration due to a very large compression force $N$. EUROCODE 2 however considers such effect including the coefficient $\alpha_{c w}$ in the analysis of the shear strength regarding web crushing, which is incorporated in the proposed simplified procedure;

The proposed NBR 6118 based procedure to compute the shear strength of hollow circular sections subjected to combined axial compressive force, bending and shear is both simple and safe.

\section{References}

[1] ACI 318-11 (2011). Building Code Requirements for Structural Concrete $(\mathrm{ACl} 318-11)$ and commentary. American Concrete Institute (ACI).Detroit, MI, Ed. 2011.

[2] JENSEN, U.G AND HOANG, L.C.(2010) "Shear Strength of Reinforced Concrete Piers and Piles with Hollow Circular Cross Section Struct" Eng. Intern, Vol. 20, March 2010, pp 260-267.

[3] KISHIDA, S.; HONRRI, M.; KAWABARA, F.; HAYASHI, S. (1998) "Experimental Study on Shear Strengh of the PHC Pile with Large Diameter.” J Struct. Const. Eng; 8 (519); 123130 (in Japanese).

[4] VÖLGYI, I., FARKAS, G., WINDISCH, A.(2014): Resistance of Reinforced Concrete members with hollow circular crosssections under combined bending and shear - Part I: Experimental Investigation. Ernst \& SohnVerlag für Architektur und technische Wissenschaften $\mathrm{GmbH}$ \& Co. KG, Berlin . Structural Concrete 15 (2014), No. 1, pp. 13-20.

[5] COLLINS, M.P.; BENTZ E.C.; KIM Y.J.(2002) "Shear Strength of Circular Reinforced Concrete Columns." In: S. M. Uzumeri symposium: Behavior of concrete structures for seismic performance. American Concrete Institute; p. 45-86.

[6] FIB Model Code For Concrete Structures 2010 (final draft), (2012)

[7] BENTZ, E.C.; VECCHIO F.J.; COLLINS, M.P.(2006). "Simplified Modified Compression Field Theory for Calculating Shear Strength of Reinforced Concrete Elements." ACI Struct J;103(4):614-24.

[8] AASHTO. LRFD (2012) Bridge design specifications and commentary. 4th ed. American Association of State Highway and Transportation Officials (AASHTO), Washington D.C, 4th ed, 2012.

[9] CSA A23.3-04 (2004) Design of Concrete Structures. Standard CAN/CSA A23.3-04, Canadian Standards Association, Mississauga, Ont.

[10] NBR 6118 (2014) Projeto de Estruturas de Concreto Procedimento, Associação Brasileira de Normas Técnicas Rio de Janeiro, RJ.

[11] VECCHIO, F. J. AND COLLINS, M.P. (1986). "The Modified Compression Field Theory for Reinforced Concrete Elements subjected to Shear" ACI Structural Journal, Vol. 83, no. 2, Mar-Apr. 1986, pp219-231. 
[12] COLLINS, M.P. AND MITCHELL, D. (1990). "Prestressed concrete structures". Publication, New Jersey, USA, 754 pp.

[13] ACI 371R (1998). Guide for the Analysis, Design, and Construction of Concrete Pedestal Water Towers. Reported by $\mathrm{ACl}$ Committee 371.

[14] EUROCODE 2 (2005). European Committee for Standartization. En 1992-1-1. Design of Concrete Structures -Part 1-1: General Rules and Rules for Building. Brussels CE, 2005

[15] REGIS P., (1990), "Resistência ao Esforço Cortante em Peças de Concreto Armado com Seção Circular Vazada" Tese de M.Sc, COPPE/UFRJ, Rio de Janeiro-RJ.

[16] RUIZ, G.; TURMO, J.; RAMOS, G. (2004) “Estudio del Comportamineto Frente al Esfuerço Cortante de Pilas Cilindricas Huecas para Puentes." Tesina UPC Barcelona, 182pp.[14]

[17] VÖLGYI, I AND WINDISCH, A.(2014): Resistance of Reinforced Concrete members with hollow circular cross-sections under combined bending and shear - Part II: New Calculation Model. Ernst \& SohnVerlag Structural Concrete 15 (2014), No. 1, pp. 13-20. 